\title{
FABULA, MONUMENTUM E A FUNDAÇÃO DE ROMA NO PREFÁCIO de TITO LÍvIO (6-9)
}

Moisés Antiqueira'

Resumo: Tito Lívio, no prefácio aos Ab urbe condita libri que compôs, exprimiu algumas considerações quanto à natureza dos fatos referentes à fundação da cidade de Roma. O objetivo deste artigo é avaliar a maneira pela qual Tito Lívio, ao trabalhar com os conceitos de fabula e monumentum, lidou com os obstáculos pertinentes à composição de uma narrativa histórica sobre as origens de Roma.

Palavras-chave: Prefácio de Tito Lívio; Historiografia romana; Fundação de Roma.

Abstract: In the Preface to his $A b$ urbe condita libri Livy expressed some thoughts about the nature of the facts in reference to the founding of the City of Rome. The aim of this work is to assess how Livy dealt with the obstacles concerning the elaboration of historical narratives on the origins of Rome, through his handling of the concepts of fabula and monumentum.

Keywords: Livy’s Preface; Roman historiography; Foundation of Rome.

Qual seria o grau de precisão factual inerente às narrativas acerca da fundação da cidade de Roma? À primeira vista, uma indagação de tal espécie poderia nos soar eminentemente moderna. Não obstante, notemos o modo como Tito Lívio se manifestou, no prefácio elaborado aos seus $A b$ urbe condita libri, em relação à "facticidade" dos relatos que remontavam aos primeiros tempos da cidade:

Quais honras são contadas antes de a cidade ter sido fundada ou no ato de sua fundação mais com fábulas poéticas [poeticis fabulis] do que com documentos incorruptos [incorruptis monumentis $]^{23}$ dos fatos, essas coisas não pretendo confirmar nem refutar. ${ }^{4}$

' Doutorando e mestre em História Social pela Faculdade de Filosofia, Letras e Ciências Humanas da Universidade de São Paulo (FFLCH/USP), sob orientação da Profa. Dra. Maria Luiza Corassin. 
Cauteloso, o historiador demonstrava que, ao final da década de 30 a.C., momento em que provavelmente compôs o prólogo à obra, ${ }^{56}$ os acontecimentos referentes aos primórdios da história de Roma suscitavam dubiedade em função mesmo da antiguidade que cercava o tema.

Desta feita, almejamos analisar determinadas passagens do prefácio liviano, especialmente da sexta à nona sentença do mesmo, nas quais se verifica que o historiador teceu comentários a respeito da natureza dos fatos por ocasião da tarefa de compor uma narrativa dedicada à "história do povo romano desde as origens da cidade". ${ }^{7} \mathrm{O}$ alvorecer de Roma configurou-se como objeto de uma interpretação, por parte de Tito Lívio, a respeito da escrita da história romana e, conseqüentemente, do ofício daqueles que empreendiam tal atividade no século primeiro antes da era cristã. Sendo assim, pretendemos apontar de que modo Tito Lívio concebeu as possibilidades de reportar os eventos do passado distante, tendo em vista a empresa que propôs concretizar.

Assim, infere-se que o historiador incluiu no prefácio de sua composição uma série de reflexões acerca das origens da cidade de Roma e da própria época em que vivia, bem como manifestou os anseios e concepções que nutria acerca da monumental obra que viria a elaborar. No que tangia à fundação da cidade, Tito Lívio discorreu sobre os problemas relativos à historicidade dos fatos, notadamente àqueles pertencentes ao passado longínquo e que demandariam maior cuidado por parte de todo o escritor, tendo em vista a complexidade comum à matéria. Esta englobaria os eventos, como assinalou Tito Lívio, que "são contados [...] mais com fábulas poéticas do que com documentos incorruptos dos fatos [...]”. ${ }^{8}$

E assim o discurso liviano situava em campos opostos dois preceitos, a fabula e o monumentum. O primeiro, diz David S. Potter, correspondia no universo grecorromano a uma modalidade discursiva vinculada ao âmbito das tragédias e das obras poéticas e, pois, deveria diferenciar-se da verdade (veritas) em conteúdo e/ou na forma. ${ }^{9}$ Portanto, a evidência fabular se encontraria intimamente associada a elementos míticos e lendários, transmitidos oralmente de geração em geração; do mesmo modo, as noções de drama e de fingimento evocariam a acepção do termo em questão. ${ }^{10}$ Cícero partia exatamente destes pressupostos quando argumentou, no tratado retórico De inventione, que a fábula seria "composta de tal sorte de fatos que não são nem verdadeiros, nem verossímeis", enquanto que a história concernia ao "relato dos feitos, distantes da memória de nossa própria época”. ${ }^{11}$

Logo, ao contrastar a fábula, por um lado, e o documento, por outro, Tito Lívio remetia à distinção metodológica entre oralidade e autópsia enquanto princípio de fundamentação do saber histórico, tal como professado por Tucídides ainda no século quinto antes de nossa era. Exatamente porque viu, ou seja, na 
condição de testemunha ocular de um fato, o historiador ateniense julgou alicerçar as informações que reportaria. ${ }^{1213}$ Assim, por exemplo, no relato tucidideano sobre a peste que grassou Atenas em 430 a.C. podemos notar a seguinte afirmação: “eu mesmo contraí o mal e vi os outros sofrendo dele". ${ }^{14}$

Neste ensejo, ao considerar o conflito que opôs os atenienses aos peloponésios como a maior de todas as guerras, ${ }^{15}$ Tucídides postulou que exporia uma reconstituição exata daquele acontecimento - no qual ele próprio ativamente tomou parte, ressalte-se - em contraposição à incerteza que caracterizava as recordações do passado mais recuado. No entender de Tucídides, afirma John L. Moles, a clareza acerca dos fatos relativos à Guerra do Peloponeso derivaria da percepção pessoal dos mesmos, bem como da necessidade de peneirar e checar junto a outrem, com a maior exatidão possível, as informações recolhidas. ${ }^{16}$ Sob a égide de tais princípios, a veracidade das proposições concernentes aos eventos demasiadamente afastados do momento em que se escreve, ou seja, do tempo da narrativa, jamais poderia ser assegurada.

Posteriormente, no século segundo a.C., observa-se que Políbio insistiria na obrigação que o historiador teria de viajar para vários lugares, a fim de estabelecer observações de caráter pessoal, isto é, diretas. ${ }^{17}$ Assim, em meio às críticas que lançou ao siciliano Timeu de Tauromênio, Políbio asseverava que "a tarefa de investigação [...] é a parte mais importante da história”. ${ }^{18}$ Como destacado por François Hartog, as posições ilustradas por Tucídides e Políbio quanto à diferenciação entre o ver e o ouvir traduziriam "uma relação com o mundo que é o cerne da civilização grega: o privilégio do olho como modo de conhecimento". ${ }^{19}$

Vale salientar que essa percepção gestada entre os helenos imprimiu sua marca na confecção da vindoura historiografia romana. Advoga John Marincola que, mesmo os autores que dissertavam sobre eventos não-contemporâneos, caso de Tito Lívio, se confrontavam com a perspectiva de que a observação pessoal consistia na melhor forma de fundamentar e reconstituir a memória do passado. ${ }^{20}$ Por conseguinte, quanto mais antigo o historiador, mais verossímil seriam as linhas por ele traçadas, uma vez que, cronologicamente mais próximo dos eventos que relatara, tal autor poderia ter inquirido ou mantido contato com indivíduos que presenciaram dados eventos e, nestes termos, teria empregado um material dotado de maior 'confiabilidade' na elaboração de seu texto. Nestes termos, a antiguidade de um autor congregaria um elemento para o qual historiadores como Tito Lívio deveriam atentar ao consultar as fontes que forneceriam as informações para a composição de sua narrativa.

Em suma, ao empregar o conceito de fabula em seu prefácio, concluir-seia que, a princípio, Tito Lívio dispensou pouca credibilidade aos acontecimentos definidos como fabulares, quais sejam, os fatos relativos aos primórdios de Roma. 
Para além, a confirmação da superioridade do documento/visual ante a fábula/oral residiria na definição, traçada pelo historiador, do primeiro como "incorrupto". ${ }^{21}$ Acrescente-se igualmente que Tito Lívio, na seqüência de seu prefácio, vislumbraria a excelência de sua obra ao imaginá-la como um "claro documento" (inlustri monumento), ${ }^{2223}$ o qual ofertava para a apreciação e utilidade do público leitor. Ao mesmo tempo, o historiador reconhecia a intangibilidade de determinados eventos do passado, haja vista pertencerem ao âmbito da fábula, escapando a quaisquer possibilidades de recordação exata. Logo, quanto às origens da cidade, Tito Lívio disporia somente de relatos para os quais ele próprio denotaria pouco crédito. Sendo assim, não restou a ele senão manter em suspenso a avaliação quanto à historicidade dos acontecimentos mais remotos: eis porque Tito Lívio finalizou sua argumentação enfatizando que "[...] essas coisas [isto é, os fatos tradicionalmente vinculados à fundação de Roma] não pretendo confirmar nem refutar". ${ }^{24}$ Neste sentido, o cético e relutante posicionamento liviano face aos primórdios da história da cidade de forma alguma surpreenderiam.

Desta maneira, Tito Lívio atestou que a manutenção da distinção metodológica entre fábula e documento, corrente no âmbito da historiografia clássica, revelar-se-ia inadequado para dada fração de sua obra, na medida em que os elementos fabulares fundamentariam os exempla referentes à fundação de Roma. Assim, no que concerne aos eventos posteriores aos inícios da cidade, seríamos levados a deduzir que o historiador os consideraria como factíveis, posto que apenas ao momento da fundação vinculavam-se "fábulas poéticas” em maior medida que os "documentos incorruptos". ${ }^{25}$

Entretanto, no preâmbulo ao livro $6,{ }^{2627}$ a partir do qual começou a narrativa da segunda metade da história romana, Tito Lívio avalia de maneira sintética a pêntade elaborada anteriormente:

Aquilo que os romanos fizeram desde a época da fundação de Roma até sua captura [por parte dos gauleses, em 390 a.C.] eu coloquei em cinco livros, coisas que são obscuras, resultado não apenas de sua excessiva antiguidade [...], mas também porque naqueles tempos a escrita, o único guardião confiável da memória dos feitos, era pouco utilizada e incomum e porque, mesmo se houvesse algo nos comentários dos pontífices e em outros registros públicos e privados, em sua maioria teriam perecido quando a cidade fora incendiada. Mais ilustre e definitivo são os feitos em época de paz e guerra que serão apresentados a partir deste ponto, o segundo [...] início da cidade. $^{28}$

O historiador permite-nos entrever a crença que depositava nos registros escritos, em razão da precisão atrelada aos mesmos, como fonte confiável para 
expor as realizações do povo romano. Neste prólogo, adequado à continuidade de sua obra, Tito Lívio retomou a tradicional diferenciação entre oralidade e escrita, reconhecendo, contudo, sua aplicabilidade somente para o conteúdo abordado a partir do livro 6, que se iniciava com a passagem transcrita acima. Podese afirmar, neste sentido, que Tito Lívio empreendeu uma revisão de sua obra, uma vez que os fatos cuja narrativa dependia da fabula no prefácio originário, isto é, aqueles relativos às origens da cidade, em verdade são assaz numerosos, posto serem obscuros os eventos que se estendiam da fundação romana até a invasão gaulesa. ${ }^{29}$ Portanto, a excessiva antiguidade e a pouca e incomum utilização da escrita obstaculizam, conforme argumentou o historiador, a reconstituição factível dos episódios incluídos nos primeiros cinco livros.

Quais pontos, pois, nortearam Tito Lívio no relato de tais eventos? A relevância destes subsistiria, aventamos, na condição de prefigurarem traços da memória da cidade e, por tabela, definidores do "ser romano". Assim, tornar-seiam imprescindíveis para a composição de um autor como Tito Lívio, cuja concepção exemplar de história atribuía aos fatos um caráter generalizante, que transpunha os limites temporais em que aqueles se encerram. Isso permitiria ao historiador construir uma seqüência inteligível de res gestae a aproximar o passado do presente, em benefício de um indivíduo ou de todo o corpo cívico romano. ${ }^{30}$

Ademais, Jacques Poucet advoga que as balizas entre fabulae e facta eram relativamente fluídas no pensamento dos antigos gregos e romanos, do que decorria a impossibilidade de classificação estrita dos primeiros séculos da história romana a partir das categorias acima mencionadas, uma vez que a fábula está igualmente presente do outro lado da fronteira e, logo, seria encarada como material histórico em potencial. ${ }^{31}$ Desta forma, sugerimos que Tito Lívio aplicou, ao elaborar o prefácio, ${ }^{32}$ o critério da fabula para caracterizar o período anterior à fundação de Roma devido à quantidade e concentração de elementos fabulares imiscuídos aos eventos circunscritos àquele momento. Por seu turno, ao fazê-lo, o historiador findava por reafirmar a importância de tais acontecimentos, visto estes contemplarem parte indispensável da tradição romana, ainda que mesclados a inúmeros traços antes ajustados à esfera das fabulae. ${ }^{33}$ Com efeito, quanto mais antigo o material à disposição, mais os historiadores clássicos - Tito Lívio incluso - se aproveitaram da tradição épica e das técnicas a ela ligadas. ${ }^{3435}$

Tal perspectiva configura o pano de fundo de uma passagem particular da narrativa liviana. Ao reportar a sentença do decênviro Ápio Cláudio, que reduziu a jovem Virgínia à escravidão, no contexto dos desmandos e da crueldade associada ao Segundo Decenvirado (450-449 a.C.), o historiador explicitou:

Qual discurso ele [isto é, Ápio Cláudio] proferiu após o decreto, porventura alguns autores antigos a verdade [verum] trans- 
mitiram: porquanto do mesmo não descubro algum que seja verossímil [veri similem], de tal sorte à indignidade do decreto, por isso exponho aquilo que se parece simplesmente consenso. ${ }^{36}$

Percebe-se que, novamente, Tito Lívio optou por suspender qualquer tipo de ajuizamento acerca da confiabilidade de um hipotético discurso que a personagem histórica Ápio Cláudio teria efetuado quando anunciada a decisão que tomara a respeito da liberdade de Virgínia. Ou melhor, o historiador evitou mesmo inserir qualquer palavra na boca do decênviro, pois não encontrou nem ao menos alguma que lhe parecesse verossímil. Logo, limitou-se meramente a relatar o acontecimento e o conteúdo do decreto. Ao que parece, o reconhecimento de dificuldades de tal ordem surge como comprovação de 'honestidade' por parte de Tito Lívio, evidenciando que ele lidaria abertamente com problemas de facticidade insolúveis, posto que não reivindicava para os primeiros livros de sua narrativa uma precisão maior do que eles poderiam oferecer.

Por seu turno, a garantia de apresentar aquilo que se parece simplesmente consenso, como mencionado no versículo acima, atesta implicitamente que o historiador teria procedido a uma investigação quanto à veracidade do fato e, ao fazê-lo, confrontou-se com uma multiplicidade de versões das quais extraiu tãosomente a informação consensualmente sublinhada dentre o hipotético leque de autores consultados. ${ }^{37}$ Esta postura reforçaria a evocação de uma imagem de 'sinceridade' liviana, quanto ao exercício de seu ofício, no desenrolar da trama narrativa.

Neste caso, a avaliação do passado como factualmente impreciso sugeriria, de forma sutil, certo grau de liberdade ao historiador em sua atividade de manipulação da tradição histórica. Similarmente, conferiria à obra que compunha papel comum às demais representações de res gestae, tais como os monumentos edilícios ou a celebração de triunfos, na medida em que sua narrativa portasse e transmitisse ao público imagens que por si veiculavam fragmentos diretos do passado. ${ }^{38}$

A narrativa liviana, com efeito, fomentaria a continuidade entre passado e presente, mantendo viva a memória dos feitos de outrora, inclusive aqueles que, por sua natureza, baseavam-se antes em fabulae que nos monumenta/documentos. Sublinhemos que a decisão de Tito Lívio em narrar a história de Roma, desde o seu começo, ainda que fabular, o distancia de analistas como Quinto Cláudio Quadrigário, cujos escritos remontam à década de 70 do primeiro século anterior à era cristã. Este último teria considerado fraudulenta a tradição histórica romana que antecedia ao ano de 390 a.C., tal como inscrita nos anais dos pontífices e, aparentemente com base nesta avaliação, teria abandonado o relato do período 
monárquico e alto-republicano e iniciado seu texto a partir dos eventos posteriores à data supracitada. ${ }^{39}$ Vale indicar que, a despeito de seus propósitos de patriotismo e entretenimento, Quadrigário igualmente pretendeu fornecer à sua narrativa feições de uma composição factualmente precisa, posto que citava uma profusão de documentos cujo intuito seria o de corroborar àquilo que reportava, ainda que em sua maior parte tal material tenha sido forjado e os detalhes e ações relatadas por ele, consequentemente, frutos de sua fértil imaginação. ${ }^{40}$

Desta feita, voltemos nosso olhar ao prefácio liviano, em que se lê:

Dá-se licença à antiguidade para que, misturando as coisas humanas às divinas, faça mais augustos os primórdios da cidade; e se a algum povo é lícito consagrar suas origens e remontar seus fundadores aos deuses, o povo romano tem essa glória de guerra. Tal como este diz que Marte muito poderoso é seu pai e também de seu fundador, assim também isso os outros povos suportem com o mesmo ânimo com que suportam o império. ${ }^{41}$

Ao asseverar que a antiguidade recebera uma licença para tornar o início das cidades mais augusto, a partir da "mistura das coisas humanas às divinas", ${ }^{42}$ o historiador saudava o povo romano, que a si próprio concedeu tal isenção, e poderia declamá-la mais que qualquer outra cidade. Tal ponto revelava um traço identitário dos romanos, qual seja, a virtude militar, resultado da presença do deus Marte no ato de fundação da cidade. Por tabela, escreve Breno Battistin Sebastiani, as origens e toda a subseqüente história de Roma se fundamentariam sobre o valor militar, fator este a tornar aceitável a outros povos a supremacia dos romanos e a construção do império. ${ }^{43}$ Por sua vez, a ênfase colocada na condição de superioridade de um povo, no caso específico o romano, denotaria a utilização de um recurso retórico familiar aos antigos, ${ }^{44}$ ecoado por Tito Lívio no versículo acima.

Nestes termos, em princípio, o argumento desenvolvido por Tito Lívio evidenciaria os dotes militares que os romanos possuíam. Tais predicados levariam os povos do mundo à conclusão objetiva de que, efetivamente, o deus da guerra interferiu nas origens da cidade de Roma. Em outras palavras, os romanos venceram os demais povos porque viviam sob os auspícios de Marte. Contudo, ao preconizar que "assim também isso os outros povos suportem com o mesmo ânimo com que suportam o império", 45 Tito Lívio imprimiu uma alteração àquela suposição inicial. Se as conquistas romanas funcionavam como o parâmetro por meio do qual os povos da Terra avaliavam a afirmação da ascendência divina sobre a fundação da cidade, logo tais povos não contemplariam a glória de Roma de modo objetivo, uma vez que contemplariam as realizações romanas enquanto 
parcela significativa que as ilustrava e sustentava, isto é, as "suportava". Neste sentido, aceitariam a origem divina de Roma à medida que se inseriam no interior do e integravam o império e, neste caso, os romanos lhes ditavam como seriam e como serão as coisas. Para tanto, escreve Gary B. Miles,

a afirmação da ancestralidade divina é justificada aqui não por causa de seu sentido literal, mas porque apropriadamente simboliza os feitos marciais dos romanos que, qualquer que seja a realidade de suas origens, têm a capacidade de obrigar os demais a concordar com aquela afirmação. ${ }^{46}$

A divina paternidade de Roma implicava uma maneira, para os povos subjugados inseridos no interior do império, de representar a si mesmos a condição subordinada em que se encontravam. Entretanto, esta história se originava no âmago da coletividade romana, tendo a construção do império permitido àquela produzi-la e reiterá-la, visto que explicitaria por quais mecanismos Roma alcançou tal posição. Contudo, há uma parcela para a qual o império do povo romano não se aplica, isto é, a si próprio. Este, no prefácio liviano, é retratado como um imperator coletivo sobre os demais povos, que imprime ordens àqueles que estão a ele sujeitos, governando a si autonomamente. ${ }^{47}$

Por outro lado, visto a imprecisão inerente à recordação deste material temporalmente longínquo, tanto o historiador quanto à multidão de escritores a qual faz alusão no prefácio ${ }^{48}$ não poderiam confirmá-lo ou negá-lo, independente da autoridade social que dispusessem. Assim, Tito Lívio retomará no prefácio contornos de dúvida similares aos anteriormente destacados no Pref. 6 e assegurará que não questionaria as opiniões relativas à ascendência de Marte sobre a fundação da cidade "ou as que lhes forem contrárias". ${ }^{49} \mathrm{O}$ emprego de expressões céticas como essa, por parte dos historiadores antigos, parece derivar da intenção por passar aos leitores uma impressão de confiabilidade ao conjunto da obra..$^{50}$ Adicione-se a isto, não obstante, a reiteração da perspectiva de que a tradição histórica trabalhada por Tito Lívio, no que concerne ao passado remoto, não permitiria uma re-elaboração precisa e confiável dos fatos, mas, ao contrário, se configura como indício da percepção que os romanos teciam acerca de si próprios. Ou seja, tal tradição afigurava-se como um registro que poderia ser utilizado enquanto base para a interpretação e perpetuação dos signos referentes à identidade coletiva. ${ }^{5152}$

Sendo assim, a remissão ao papel de Marte no ato de fundação da cidade constitui outro ponto com o qual o historiador não reúne condições suficientes para concordar ou refutar. Todavia, tamanha ambiguidade não o impediu de mencioná-lo, porquanto preconizava traços que caracterizavam o povo romano na condição de militarmente vitorioso, em uma relação de alteridade face aos demais povos a ele subordinados. 
Ademais, consideramos igualmente que Tito Lívio estendeu, no interior do próprio prefácio ao conjunto da obra, o arco temporal dos fatos que julgou mais apropriado ao trabalho dos poetas, como definido em relação à fundação da Roma. ${ }^{53}$ Nota-se que o Pref. 8, ${ }^{5455}$ ao preceder e se interligar à primeira sentença do Pref. 9, ${ }^{5657}$ alimenta a postura cética e cautelosa grafada no Pref. 6, porém sem limitá-la apenas aos eventos que caracterizaram o início de Roma, articulando-a a um período bastante posterior, em que o poder dos romanos ultrapassava os estreitos limites da cidade. ${ }^{58}$

Neste sentido, o prólogo ao livro 6 que compunha a narrativa ratifica e esclarece uma proposição implícita ao prefácio liviano originário. Logo, o historiador transmitiu aos leitores a perspectiva de que a facticidade da tradição histórica romana seria, no que concerne a determinados pontos, inatingível, noção retomada e causalmente explicitada no decorrer da própria narrativa em si. ${ }^{5960}$ Para além, pode-se afirmar que os versículos 6-8 do prefácio aos Ab urbe condita libri professam, em verdade, uma consciente opção metodológica por parte de Tito Lívio. ${ }^{61}$ Escolha esta que se revelaria essencial e deliberada, posto que o historiador preocupou-se em esclarecê-la sob o plano do concreto labor historiográfico, ou seja, antepondo ao relato dos feitos dos romanos a partir da invasão dos gauleses no início do século quarto a.C. uma nota por meio da qual passava em revista a natureza dos eventos reportados na pêntade anterior.

Desta maneira, Tito Lívio demonstrou estar ciente da impossibilidade de reconstrução precisa dos fatos referentes aos primeiros séculos da história de Roma. Para ilustramos tal assertiva, citemos o registro de uma revolta dos habitantes de Âncio contra os romanos, que teria sido levada a cabo no ano de 459 a.C., para a qual Tito Lívio não ousou atestar se teria de fato ocorrido, tendo em vista que "autores mais antigos" (vetustiores scriptores) não a relataram. ${ }^{62} \mathrm{Um}$ empecilho de tal ordem, entretanto, não seria suficiente para conduzir o historiador a excluir de sua narrativa a menção ao acontecimento, pois que o objetivo liviano focar-se-ia menos na reconstrução factual que na rememoração do passado romano remoto.

Asseveramos que, à medida que o historiador propôs a elaboração de uma obra destinada a preservar, do olvido provocado pelo tempo, a memória dos feitos que possibilitaram a construção e ampliação do poderio dos romanos, ${ }^{63}$ expondoos ao ajuizamento dos leitores, o monumentum/documento liviano poderia exercer função similar àquela própria dos monumentos edilícios dispostos no espaço urbano ao alcance do olhar de toda a coletividade. ${ }^{64} \mathrm{Em}$ outras palavras, o texto de Tito Lívio configuraria outro mecanismo perpetuador de res gestae nos interstícios da cultura romana, transmitindo uma representação do passado e, enquanto tal, matizaria os possíveis inconvenientes que um fato histórico mais próximo ao 
campo da fabula poderia impor ao historiador. Sendo assim, Tito Lívio ofertou um instrutivo ponto de vista a respeito da dicotomia entre fabula e monumentum nos meandros da escrita da história em Roma, manipulando aquela conforme as necessidades que o ofício, a narrativa dos feitos ocorridos durante os primeiros séculos da história romana, demandava.

\section{NOTAS}

${ }^{2} \mathrm{O}$ vocábulo latino monumentum, utilizado pelo historiador na passagem em questão, significa "o que traz alguma coisa à lembrança", "lembrança" ou "penhor", donde passou a referir-se a "edificação", na medida em que esta evocasse a recordação de algo. A utilização do termo monumentum por parte de Tito Lívio indica a ideia de documentação escrita. Como assinala Jacques Le Goff, para tal noção usavase indistintamente, até o final dos setecentos, os vocábulos "documento" e "monumento" enquanto sinônimos.

${ }^{3}$ Ver LE GOFF, Jacques. Documento/monumento. In: História e memória. Trad. Bernardo Leitão et al. 3. ed. Campinas: Unicamp, 1994. P. 536.

${ }^{4}$ TITO LíVIO. Ab urbe condita, Pref. 6. Tradução: Breno Battistin Sebastiani,. Tito Lívio e Cipião Africano: a construção da personagem histórica. Dissertação - Mestrado em História - Faculdade de Filosofia, Letras e Ciências Humanas, Universidade de São Paulo, São Paulo, 2002. P. 22.

${ }^{5}$ BURTON, Paul J. The last Republican historian: a new date for the composition of Livy's first pentad. Historia: Zeitschrift für Alte Geschichte, v.49, n.4, p.444, Sttutgart, 2000. Proposição similar se encontra em MAZZA, Mario. La praefatio di Livio: una rivisitazione. In: TROIANI, Luciano; ZECCHINI, Giuseppe (a cura di). La cultura storica nei primi due secoli dell'impero romano. Roma: "L'Erma" di Bretschneider, 2005. P. 56.

${ }^{6}$ Embora, dentro dos limites do presente artigo, não nos ocupemos em discorrer acerca das dissonâncias que regem o moderno debate historiográfico acerca da datação do prefácio liviano, partilhamos dos pontos de vista - expostos pelos autores supramencionados - que delimitam a preparação daquele em fins dos anos 30 a.C., quando as guerras civis estavam perto de seu término ou recentemente finalizadas. Em resumo, não se observava ainda a solidificação do poder de Otaviano/Augusto à frente do mundo romano.

7 TITO LÍVIO. Ab urbe condita, Pref. I. A edição utilizada no tocante ao prefácio de Tito Lívio é a seguinte: LIVY. Livy, with an English translation in fourteen volumes. I, Books I and II. Translated by B. O. Foster. Cambridge, MA: Harvard University Press; London: Heinemann, 1988. (Loeb Classical Library).

8 TITO LÍVIO. Ab urbe condita, Pref. 6.

9 POTTER, David S. Literary texts and the Roman historian. New York; London: Routledge, 1999. P. 14.

10 MILES, Gary B. Livy: reconstructing early Rome. Ithaca; London: Cornell University Press, 1995. P. 16.

" CÍCERO, Marco Túlio. De inventione, I.19.27. Emprega-se aqui a edição organizada por Bulmaro Reyes Coria. In: CICERÓN. De la invención retórica. México, DF: UNAM, 1997. (Bibliotheca scriptorum Graecorum et Romanorum Mexicana).

12 Ressalve-se, não obstante, que ao condicionar a recolha das informações à presença aos acontecimentos, Tucídides impunha a si próprio um impasse quanto ao efetivo desenrolar de seu labor, posto que, sobre um mesmo fato presenciado por uma gama de indivíduos, o historiador poderia defrontarse com relatos divergentes em igual proporção.

13 Para tanto, ver MURARI PIRES, Francisco. A retórica do método (Tucídides 1.22 e II.35). Revista de História, São Paulo, n. I38, p. I0, jan-jun 1998.

14 TUCÍDIDES. História da Guerra do Peloponeso, 2.48. 18- 19. Tradução de Mário da Gama Kury. In: TUCÍDIDES. História da Guerra do Peloponeso. Brasília: Editora da UnB, 1982. 
${ }_{15}$ TUCÍDIDES. História da Guerra do Peloponeso, 1.21.2.

16 MOLES, John L. Truth and untruth in Herodotus and Thucydides. In: GILL, Christopher; WISEMAN, Timothy Peter. (ed.). Lies and fiction in the ancient world. Austin: University of Texas Press, 1993. p. 107.

${ }^{17}$ Cf. FORNARA, Charles William. The nature of history in ancient Greece and Rome. Berkeley; London: University of California Press, 1983. P. 48.

18 POLÍBIO. Histórias, 12.4c.3. Para tanto, consultamos a seguinte edição: POLYBIUS. The histories. IV, Books IX-XV. Translated by W. R. Paton. Cambridge, MA: Harvard University Press, 1954. (Loeb Classical Library).

19 HARTOG, François. Memória de Ulisses. Narrativas sobre a fronteira na Grécia antiga. Tradução de Jacyntho Lins Brandão. Belo Horizonte: UFMG, 2004. P. 14.

20 MARINCOLA, John. Authority and tradition in ancient historiography. Cambridge: University Press, 1997. P. 28I.

21 TITO LÍVIO. Ab urbe condita, Pref. 6.

22 "Sobretudo é salutar e frutífero no conhecimento dos fatos: que tu contemples todo tipo de exemplos [exempla] que são testemunhos dispostos em um claro documento; a partir de então o que imitarás para teu benefício e o de tua república, e aquilo que, vergonhoso pelo início ou pelo resultado, evitarás".

${ }^{23}$ Cf. TITO LíVIO. Ab urbe condita, Pref. I0. Tradução de SEBASTIANI, Breno Battistin. Tito Lívio e Cipião Africano: a construção da personagem histórica. P. 22.

${ }^{24}$ TITO LÍVIO. Ab urbe condita, Pref. 6. Cf. POUCET, Jacques. Temps mythique et temps historique. Les origines et les premiers siècles de Rome. Gérion, n.5, p.77, Madrid, 1987.

${ }^{25}$ TITO LíVIO. Ab urbe condita, Pref. 6.

26 Tito Lívio organizou sua obra, ao menos entre os livros I e 45, em pêntades e décadas. O breve prefácio ao livro 6 delimita claramente os cinco livros iniciais enquanto unidade composicional.

${ }^{27}$ Para tanto, cf. STADTER, Philip A. The structure of Livy's history. Historia: Zeitschrift für Alte Geschichte. v.21, n.2, p.302, Sttutgart, 1972.

28 TITO LÍVIO. Ab urbe condita, 6.I.I-3. Utilizamos a seguinte edição: LIVY. Livy, with an English translation in fourteen volumes. III, Books V-VII. Translated by B. O. Foster. Cambridge, MA: Harvard University Press; London: Heinemann, 1996. (Loeb Classical Library).

29 TITO LÍVIO. Ab urbe condita, 6.I.I.

${ }^{30}$ Cf. TITO LíVIO. Ab urbe condita, Pref. IO.

${ }^{31}$ POUCET, Jacques. Temps mythique et temps historique. Les origines et les premiers siècles de Rome. p. 82. Tal é a condição atestada por Tito Lívio ao rever os eventos reportados no âmbito dos cinco primeiros livros da obra tomados em seu conjunto. Cf. TITO LÍVIO. Ab urbe condita, 6. I . I-3.

${ }^{32}$ Cf. TITO LívIO. Ab urbe condita, Pref. 6.

${ }_{33}$ POUCET, Jacques. Temps mythique et temps historique. Les origines et les premiers siècles de Rome. p. 83.

${ }^{34}$ MOLES, John L. Truth and untruth in Herodotus and Thucydides. p. 103.

${ }^{35}$ De maneira similar, Timothy Peter Wiseman argumenta que um dos indicadores adequados para se vislumbrar a inserção da historiografia no escopo intelectual do mundo grecorromano seria justamente a proximidade entre a prática do historiador com aquela do poeta, na medida em que, não raro, ambos trabalhavam com um mesmo material, qual seja, os grandes eventos dignos de registro, a descrição do local onde aqueles teriam ocorrido, assim como os feitos de um célebre comandante militar. Tais temas abriam a possibilidade ao historiador, tanto quanto ao poeta, de conferir brilho e dramaticidade à respectiva obra que elaborassem, em função das qualidades estilísticas e literárias das quais demonstrassem esmero. Cf. WISEMAN, Timothy Peter. Practice and theory in Roman historiography. History: The Journal of the Historical Association, v.66, n.218, p.392, London, 1981.

${ }^{36}$ TITO LÍVIO. Ab urbe condita, III, 47, 5. Consultamos a edição que se segue: LIVY. Livy, with an English translation in fourteen volumes. II, Books III-IV. Translated by B. O. Foster. Cambridge, MA: Harvard University Press; London: Heinemann, 1984. (Loeb Classical Library). 
${ }^{37}$ BOLCHAZY, Ladislaus J. Livy's moral employment of history and the ius hospitii. In: Hospitality in Antiquity: Livy's concept of its humanizing force. Chicago: Ares, 1995. P. 82.

38 MILES, Gary B. Livy: reconstructing early Rome. P. 17.

${ }^{39}$ FRIER, Brian Woodward. Libri Annales Pontificum Maximorum. The origins of the annalistic tradition. Rome; Ann Arbor: University of Michigan Press, 1979. P. 276. À guisa de ilustração, os fragmentos mais antigos da narrativa de Quadrigário remetem-se à Batalha do rio Ália, afluente do Tibre, em que os romanos foram derrotados pelos invasores gauleses em 390 a.C. Ernest Badian sugere que o analista talvez tenha confeccionado uma introdução em que delinearia os eventos anteriores ao saque gaulês de Roma, porém sustenta que não há razão para crermos que Quadrigário abordou de modo extenso a história primitiva da cidade, uma vez que os fragmentos de seus anais não evidenciam tal perspectiva. Cf. BADIAN, Ernest. The early historians. In: DOREY, Thomas Alan (ed.). Latin historians. New York: Basic Books, 1966. P. 18.

${ }^{40}$ BADIAN, Ernest. The early historians. p. 19.

4I TITO LíVIO. Ab urbe condita, Pref. 7. Tradução: Breno Battistin Sebastiani. Tito Lívio e Cipião Africano: a construção da personagem histórica. P. 22.

${ }^{42}$ Cf. TITO LÍVIO. Ab urbe condita, Pref. 7.

${ }^{43}$ SEBASTIANI, Breno Battistin. Tito Lívio e Cipião Africano: a construção da personagem histórica. P. 30.

${ }^{44}$ EDWARDS, Catherine. Writing Rome: textual approaches to the city. Cambridge: University Press, 1996. P. 20.

${ }^{45}$ Cf. TITO LíVIO. Ab urbe condita, Pref. 7.

${ }^{46}$ MILES, Gary B. Livy: reconstructing early Rome. P. 138-139.

${ }^{47}$ SAILOR, Diane. Dirty linen, fabrication and the authorities of Livy and Augustus. Transactions and Proceedings of the American Philological Association, v. I36, p.350, Baltimore, 2006.

${ }^{48}$ Cf. TITO LíVIO. Ab urbe condita, Pref. 3.

${ }^{49}$ Cf. TITO LÍVIO. Ab urbe condita, Pref. 8.

${ }^{50}$ WISEMAN, Timothy Peter. Lying historians: seven types of mendacity. In: GILL, Christopher; WISEMAN, Timothy Peter (ed.). Lies and fiction in the ancient world. Austin: University of Texas Press, 1993. P. 135.

${ }^{51}$ Como assevera Juliana Bastos Marques, Tito Lívio citou a origem mítica da cidade de Roma "justamente porque é simbólica, vinda de uma tradição amplamente reconhecida em sua época, e serve como legitimadora de sua escolha ao abordar o problema da verdade no trabalho com os relatos mais antigos".

52 Cf. MARQUES, Juliana Bastos. Tradição e renovações da identidade romana em Tito Lívio e Tácito. 2007. Tese (Doutorado em História) - Faculdade de Filosofia, Letras e Ciências Humanas, Universidade de São Paulo, São Paulo, 2007. P. 34.

${ }_{53}^{53}$ Cf. TITO LÍVIO. Ab urbe condita, Pref. 6.

54 "Mas não questionarei estas opiniões ou as que lhes forem contrárias".

55 TITO LÍVIO. Ab urbe condita, Pref. 8.

56 "Cada um por si as analise agudamente, qual vida, que costumes existiram, devido a que homens e por quais artes interna e externamente o império tenha sido alcançado ou aumentado".

57 TITO LívIO. Ab urbe condita, Pref. 9. Tradução de Breno Battistin Sebastiani. Tito Lívio e Cipião Africano: a construção da personagem histórica. P. 22.

${ }^{58}$ Como se denota a partir da leitura dos elementos listados na primeira parte do Pref. 9. Cf. acima, n. 49.

59 Isto é, por intermédio do preâmbulo ao livro 6, ao qual por ora nos referimos.

${ }^{60}$ Cf. TITO LÍVIO. Ab urbe condita, 6.I.I-3.

${ }_{61}$ MAZZA, Mario. La praefatio di Livio: una rivisitazione. P. 43.

${ }^{62}$ Cf. TITO LÍVIO. Ab urbe condita, 3.23.7.

${ }_{63}$ Tal como se vislumbra em TITO LíVIO. Ab urbe condita, Pref. 9.

${ }^{64}$ MILES, Gary B. Livy: reconstructing early Rome. p. 17. 